\title{
Natural Lignocellulosic Fibers as Engineering Materials-An Overview
}

\author{
SERGIO NEVES MONTEIRO, FELIPE PERISSÉ DUARTE LOPES, \\ ANDERSON PAULA BARBOSA, ALICE BARRETO BEVITORI, \\ ISABELA LEÃO AMARAL DA SILVA, and LUCAS LOPES DA COSTA
}

\begin{abstract}
Recent investigations on the tensile properties of natural cellulose-based fibers revealed an increasing potential as engineering materials. This is particularly the case of very thin fibers of some species such as sisal, ramie, and curaua. However, several other commonly used fibers such as flax, jute, hemp, coir, cotton, and bamboo as well as less known bagasse, piassava, sponge gourde, and buriti display tensile properties that could qualify them as engineering materials. An overview of the strength limits attained by these fibers is presented. Based on a tensile strength $v s$ density chart, it is shown that natural fibers stand out as a relevant class of engineering materials.
\end{abstract}

DOI: $10.1007 / \mathrm{s} 11661-011-0789-6$

(C) The Minerals, Metals \& Materials Society and ASM International 2011

\section{INTRODUCTION}

IT was not until the classical work of Ashby ${ }^{[1]}$ that different classes of engineering materials could be conceived in contrast to the basic scientific distinction of metals, polymers, and ceramics. The concept of the Materials Property Chart ${ }^{[1,2]}$ permitted classification of engineering materials by their proper field in a plot of a pair of properties. Furthermore, these charts could be used to select the materials with the best performance, through specific guidelines, associated with modes of loading for a given engineering application. In his original work, ${ }^{[1]}$ Ashby considered eight basic classes of engineering materials: polymers foams, elastomers, engineering polymers, porous ceramics, engineering alloys, engineering ceramics, engineering composites, and woods. Among these eight classes, the only one related to natural fibers was wood. This original idea presents no restrictions to include other possible classes. In fact, Ashby and Greer, ${ }^{[3]}$ using charts based on the pair combination of three properties, elastic limit (yield strength), Young modulus, and fracture toughness, introduced new ellipses enclosing the range of values associated with bulk metallic glasses (BMGs). According to the charts, BMGs now stand out as new highstrength structural materials lying at the upper edge of other metallic alloys.

In a seminal review work, Bledzki and Gassan ${ }^{[4]}$ reported on the structure and properties of cellulose-rich

SERGIO NEVES MONTEIRO, Full Professor, FELIPE PERISSÉ DUARTE LOPES, ANDERSON PAULA BARBOSA, ALICE BARRETO BEVITORI, ISABELA LEÃO AMARAL DA SILVA, and LUCAS LOPES DA COSTA, Postgraduate Students, are with the Laboratory for Advanced Materials - LAMAV, State University of the Northern Rio de Janeiro, UENF, CEP: 28013-602 - Campos dos Goytacazes, Rio de Janeiro, Brazil. Contact e-mail: sergio.neves@ig. com.br

Manuscript submitted April 5, 2011.

Article published online July 15, 2011 natural fibers. These fibers obtained from vegetables are also known as plant fibers or lignocellulosic fibers (LCFs). The latter, the preferred term in this overview, indicates the predominance of lignin and cellulose in a natural plant fiber structure. Such structure could reach tensile strength levels close to the values for glass fibers. For instance, flax would have an upper limit of $1035 \mathrm{MPa}$. In this work, ${ }^{[4]}$ the authors also emphasized results on pineapple fiber, indicating that a decrease in fiber fineness (equivalent diameter) leads to higher strength. Actually, correlations between the dimensions of LCFs and related mechanical properties were investigated earlier. ${ }^{[5-9]}$ For fibers extracted from the mesocarp of the coconut fruit, known as coir fibers, the elastic modulus gradually decreases with increasing diameter, within the entire range investigated. ${ }^{[5]}$ For fibers obtained from the stem of the banana tree, a decrease in the tensile strength was correlated with the fiber test length. ${ }^{[6]}$ For sisal fibers, within the diameter range of 100 to $300 \mu \mathrm{m}$, a decrease in strength was also found for increasing fiber test length. ${ }^{[7]}$ Regarding the fibers collected from the leaves of the pineapple plant, the strength was reported to decrease with the diameter within the interval from 45 to $205 \mu \mathrm{m} .{ }^{[8]}$ For palmirah fibers, the strength and the elongation decreased with the test length. ${ }^{[9]}$

Recent works ${ }^{[10-19]}$ have shown that not only pineapple but also many LCF species display an inverse correlation between the fiber diameter and its tensile strength. This appears to be a common feature to all fibers owing to the role played by microstructural defects and an intrinsic statistical distribution of microfibril strength. ${ }^{[12-16]}$ As a consequence of the inverse correlation, tensile strengths comparable to or even above those attained by conventional high-strength lowalloy steels were exhibited by several LCFs with the additional advantage of a much lower density. Previous works ${ }^{[4,20-22]}$ reported on relatively high tensile strengths for a restricted number of LCFs; however, no systematic 
investigation was attempted to characterize a location or field of properties associated with a corresponding class of engineering material. Therefore, the objective of the present work (PW) was to overview earlier as well as recent works on stronger very thin LCFs and to locate them in an Ashby's tensile strength vs density chart.

\section{GENERAL ASPECTS OF THE LCFS}

Since last decade, a considerable amount of information on natural fibers was presented in review articles. ${ }^{[4,20-23]}$ It is beyond the scope of this work to discuss all subjects related to LCFs in those articles. However, some points are relevant to the proposed objective and are now considered. Bledzki and Gas$\operatorname{san}^{[4]}$ indicated that a single fiber of a plant is a complex natural composite consisting of several cells. These cells are composed of cellulose microfibrils connected by lignin and hemicelluloses. The lignin is an amorphous binder with both aliphatic and aromatic polymeric constituents, whereas the hemicellulose comprises polysaccharides that remain associated with the cellulose even after lignin is removed. ${ }^{[4]}$ The ratio between cellulose and lignin/hemicelluloses as well as the spiral angle of the microfibrils vary from one natural fiber to another. Since these structural parameters determine the mechanical properties, each kind of LCF presents distinct properties.

As stated by Mohanty et al., ${ }^{[20]}$ the properties of fibers of the same species may vary considerably. This depends on whether the fiber is taken from stems or leaves, the quality of the plant location, the age of the plant, and the preconditioning. By contrast, synthetic fibers such as glass, carbon, and aramid can be uniformly produced with a definite range of properties, as illustrated by the homogeneous microstructural aspect in Figure 1. Consequently, in comparison with synthetic fibers, LCFs are nonuniform in properties, dimensionally limited, and microstructurally heterogeneous, as exemplified for a few LCFs in Figure 2. Eichhorn et al. ${ }^{[21]}$ emphasized the role of existing defects in natural cellulose fibers. Since defect-free LCFs may not be possible in nature, their properties are conditioned by the amount and distribution of flaws and imperfections.

Another important difference between natural and synthetic fibers is the interaction with water. As mentioned by Nabi Saheb and Jog, ${ }^{[22]}$ cellulosic fibers are hydrophilic and absorb moisture. In a normal ambient condition, the moisture content of LCFs can vary between 5 and 10 pct. In case the fiber is used as a
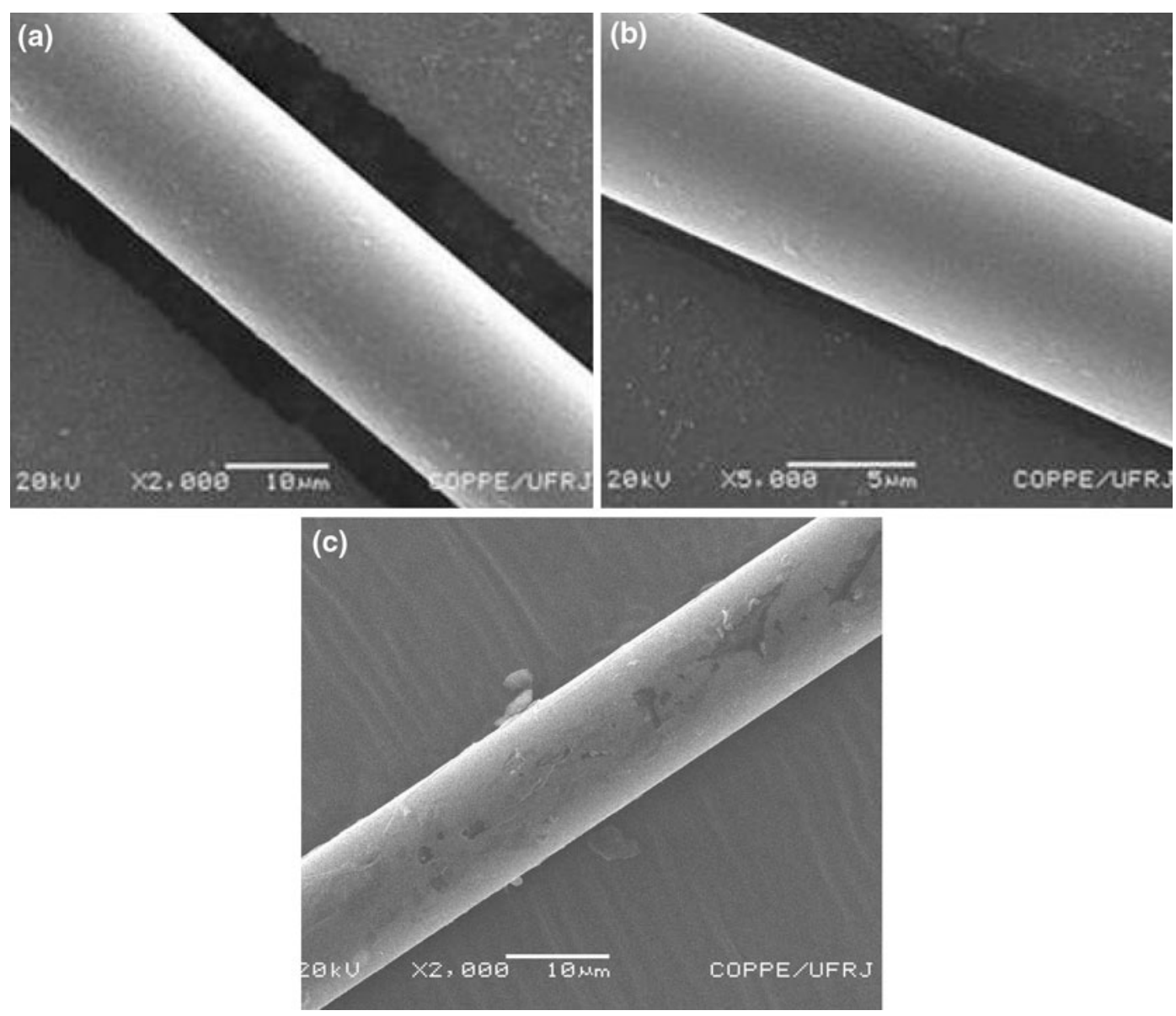

Fig. 1-SEM view of synthetic fibers: (a) glass, (b) carbon, and (c) aramid. 

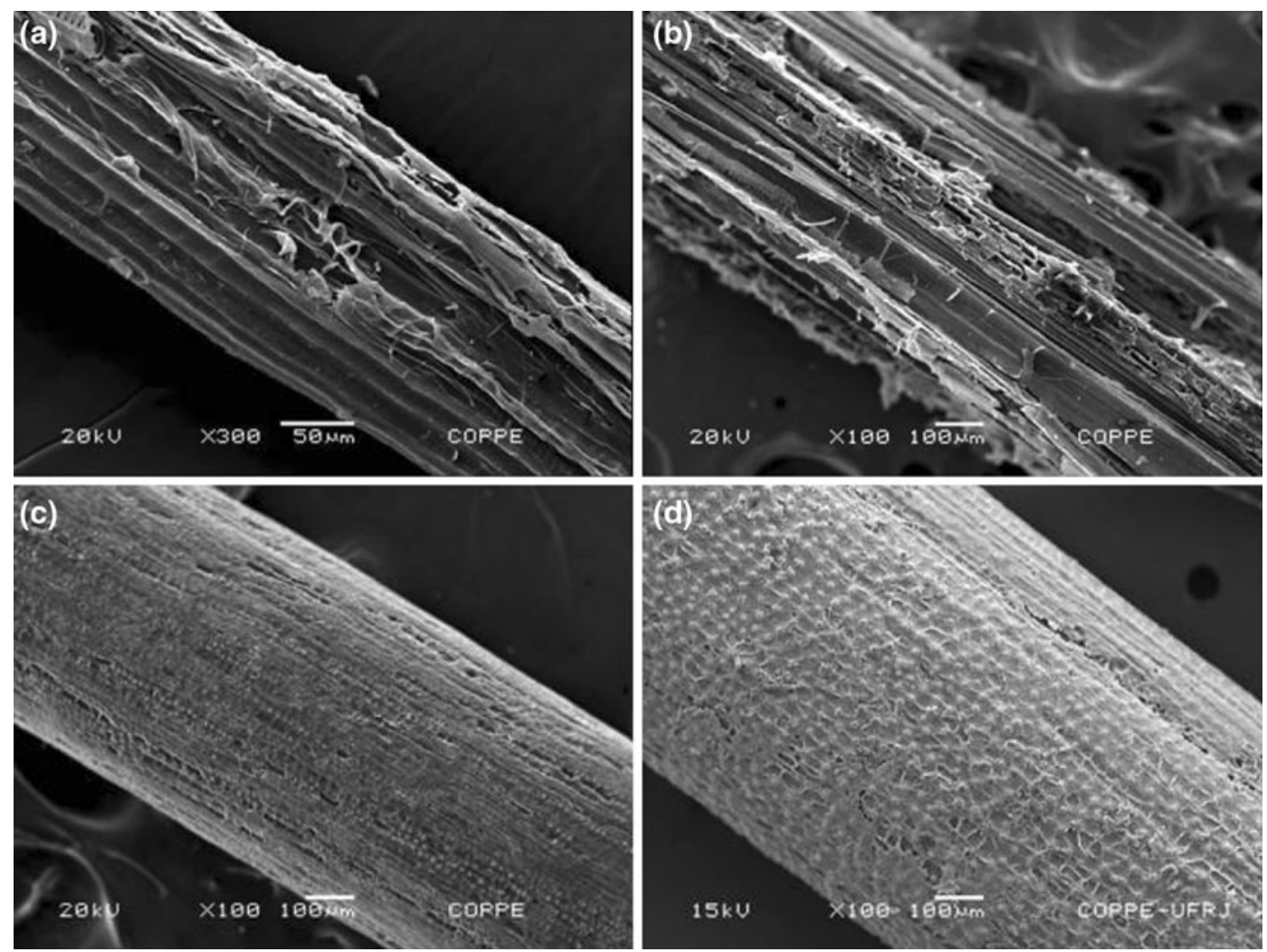

Fig. 2-SEM view of natural lignocellulosic fibers: (a) sisal, (b) bamboo, (c) coir, and (d) piassava.

polymer composite reinforcement, this can lead to dimensional variations and can affect the mechanical properties. According to Bledzki and Gassan, ${ }^{[4]}$ drying of fiber before processing is an important factor, because water on the fiber surface acts as a separating agent in the interface with a hydrophobic polymer matrix. Additionally, due to water evaporation, voids may appear in the matrix.

A commonly proposed solution to improve the LCF reinforced polymer interfacial adhesion is the fiber pretreatment. ${ }^{[4,20-24]}$ Both cellulose and lignin possess hydroxyl groups that may be involved in the hydrogen bonding within the fiber structure. Surface chemical modification can activate these groups and effectively improve interfacial adhesion between the fiber and the polymeric matrix. ${ }^{[22]}$ Common examples of these pretreatments are mercerization, acrylation, acetylation, etherification, benzoylation, and silane reaction. Kalia et al. ${ }^{[24]}$ affirmed that, in addition to chemical modification of the surface, pretreatments can also be used to clean the fiber surface, stop the moisture absorption process, and increase the surface roughness. In these authors' review, ${ }^{[24]}$ an extended list of composites reinforced with pretreated LCFs, such as hemp, knaf, jute, flax, sugarcane bagasse, coir, roselle, ramie, pineapple, abaca, sisal, henequen, cotton, wheat straw, rice husk, and wood wool, was presented.

Regarding the use of pretreatment to increase the surface roughness, indicated in the work of Kalia et al., ${ }^{[24]}$ the specific micromorphology of each LCF should be taken into consideration. In principle, some fibers have considerable surface roughness (Figure 2), which may contribute to a polymeric matrix adhesion. ${ }^{[25]}$ In this case, chemical pretreatments may not be effective and the resulting fiber degradation could impair the composite matrix reinforcement effect.

In spite of the drawbacks, the LCFs possess important advantages over synthetic fibers, particularly the Eglass. ${ }^{[26]}$ It has been pointed out that LCFs are comparatively less expensive, lighter, nonabrasive to processing equipment, and more flexible, which contributes to tougher composites. Social and environmental issues are today the most valuable advantages. Many LCFs are native or cultivated in developing regions and represent a major source of income to the local populations. ${ }^{[23]}$ Being renewable, degradable, recyclable, and neutral with respect to $\mathrm{CO}_{2}$ emissions, LCFs are less polluting and also contribute to preventing global warming. ${ }^{[25]}$

\section{DENSITY AND STRENGTH OF LCFS}

The comparatively lower density of all LCFs so far investigated is a major advantage for possible uses as engineering materials. This is especially the case of applications as reinforcement of lighter composites in automobile components. ${ }^{[27-30]}$ Table I presents the density of several LCFs reviewed in this work. Some are well known and common (cotton, jute, hemp, flax, sisal, 
Table I. Density and Mechanical Properties of Selected LCFs

\begin{tabular}{|c|c|c|c|c|c|}
\hline Lignocellulosic Fiber & $\begin{array}{l}\text { Density } \\
\rho\left(\mathrm{g} / \mathrm{cm}^{3}\right)\end{array}$ & $\begin{array}{c}\text { Tensile Strength } \\
\sigma(\mathrm{MPa})\end{array}$ & $\begin{array}{l}\text { Young's Modulus } \\
\text { (GPa) }\end{array}$ & $\begin{array}{c}\text { Maximum } \\
\sigma / \rho \\
\left(\mathrm{MPa} \cdot \mathrm{cm}^{3} / \mathrm{g}\right)\end{array}$ & References \\
\hline Bagasse (Saccharum officinarum) & 0.34 to 0.49 & 135 to 222 & 15 to 17 & 493 & 23 \\
\hline Bamboo (Bambusa vulgaris) & 1.03 to 1.21 & 106 to 204 & - & - & $\mathrm{PW}^{*}$ \\
\hline Banana (Musa sapientum) & 0.67 to 1.50 & 700 to 800 & 27 to 32 & 1194 & 23, PW \\
\hline Buriti (Mauritia flexuosa) & 0.63 to 1.12 & 129 to 254 & - & 403 & PW \\
\hline Coir (Cocos nucifera) & 1.15 to 1.52 & 95 to 220 & 4 to 6 & 191 & 23,24 \\
\hline Cotton (Gossypium M.) & 1.51 to 1.60 & 287 to 800 & 6 to 13 & 530 & $4,20-24$ \\
\hline Curaua (Ananas erectifolium) & 0.57 to 0.92 & 117 to 3000 & 27 to 80 & 2193 & $23, \mathrm{PW}$ \\
\hline Flax (Linum usitatissimum) & 1.30 to 1.50 & 344 to 1035 & 26 to 28 & 496 & 4,21 \\
\hline Hemp (Cannabis sativa) & 1.07 & 389 to 690 & 35 & 649 & 21,22 \\
\hline Jute (Corchorus capsularis) & 1.30 to 1.45 & 393 to 800 & 13 to 27 & 615 & $4,20,23, \mathrm{PW}$ \\
\hline Piassava (Attalea funifera) & 1.10 to 1.45 & 109 to 1750 & 5 to 6 & 1591 & $17,23, \mathrm{PW}$ \\
\hline Pineapple (Ananas comoscus) & 1.44 to 1.56 & 362 to 1627 & 35 to 83 & 1130 & 8,23 \\
\hline Ramie (Boehmeria nivea) & 1.5 & 400 to 1620 & 61 to 128 & 1080 & $4,20,21,23, \mathrm{PW}$ \\
\hline Sisal (Agave sisalana) & 1.26 to 1.50 & 287 to 913 & 9 to 28 & 725 & $4,20-23, \mathrm{PW}$ \\
\hline Soft wood (spruce) & 0.46 to 1.50 & 112 to 1000 & 11 to 40 & 2174 & $4,31,32$ \\
\hline Hard wood (birch) & 0.67 to 1.50 & 300 to 1500 & 30 to 80 & 2239 & $4,31,32$ \\
\hline E-glass & 2.50 to 2.58 & 2000 to 3450 & 70 to 73 & 1380 & 4,31 \\
\hline Carbon & 1.78 to 1.81 & 2500 to 6350 & 230 to 400 & 3567 & 4,31 \\
\hline Aramid & 1.44 & 3000 to 4100 & 63 to 131 & 2847 & 4,31 \\
\hline
\end{tabular}

*PW: present work.

and coir); others are known but less used (ramie, banana, pineapple, and bamboo) and others relatively unknown (curaua, piassava, sugarcane bagasse, and buriti). In this table, the densities of three structural synthetic fibers are also compared. The interval of values for each fiber corresponds to the maximum and minimum limits obtained in the references. The abbreviation $\mathrm{PW}$ in the references refers to nonpublished results obtained in this work. All together, the range of LCF densities extends from 0.45 to $1.60 \mathrm{~g} / \mathrm{cm}^{3}$. In addition to LCFs, Table I also presents the density and tensile strength for wood fibers ${ }^{[31]}$ and the main structural synthetic fibers. ${ }^{[4,32]}$

\section{EXPERIMENTAL RESULTS}

Regarding the results obtained in the PW, it should be mentioned that the tensile properties were determined by precise diameter measurements. This was conducted in a profile projector at different points along the fiber axis, with the smaller and the higher measured values at each point. By this technique, the average corresponds to an equivalent diameter. The already discussed heterogeneous characteristics of the $\mathrm{LCFs}^{[25]}$ are associated with a broad variation of diameter for each species. Diameter intervals were defined according to the natural variation found in the experimental lots of each fiber. Specific lot suppliers and as-received conditions are given elsewhere. ${ }^{[10-19]}$ The statistical distribution of diameters was based on 100 randomly picked fibers from the lots. For each type of fiber overviewed in the PW, histograms corresponding to the frequency of diameter distribution were obtained ${ }^{[10-19]}$ and reproduced in Figure 3. Diameters and cross-sectional areas along the fiber length were evaluated by means of profile projector measurements. It is worth mentioning that the limit number of fibers about 1000 per lot imposes a limitation to the range of intervals in Figure 3. If lots with a greater number of fibers were investigated, maybe even thicker and thinner fibers possibly would be found, extending the range of the histograms.

For the tensile tests, 20 fibers were selected with a diameter within each interval of every histogram in Figure 3. As a testing procedure, each fiber sample was sectioned with a total length of $200 \mathrm{~mm}$. The gage length of $100 \mathrm{~mm}$ allowed $50 \mathrm{~mm}$ at the fiber's extremities to be held by the grips of the machine. Pieces of cardboard were glued to the ends of the fiber sample to avoid direct contact of the fiber surface to the grip. This procedure permitted a tied holding and prevents slippage without damaging the fiber. Tensile tests were conducted in a model 5582 universal INSTRON* or in a model DL

*INSTRON is a trademark of Instron Brasil, Barueri, SP, Brazil.

$10000 \mathrm{EMIC}^{* *}$ machine, whichever was available. The

**EMIC is a trademark of EMIC Equipamentos e Sistemas de Ensaio LTDA, São José dos Pinhais, PR, Brazil.

test temperature was an acclimatized $298 \mathrm{~K}\left(25^{\circ} \mathrm{C}\right)$. A constant deformation velocity of $1 \mathrm{~mm} / \mathrm{s}$, corresponding to a strain rate of $10^{-2} \mathrm{~s}^{-1}$, was used. The fiber strength was statistically evaluated by means of the Weibull analysis. It was observed that the variability of both the equivalent diameter and the mean cross-sectional area 

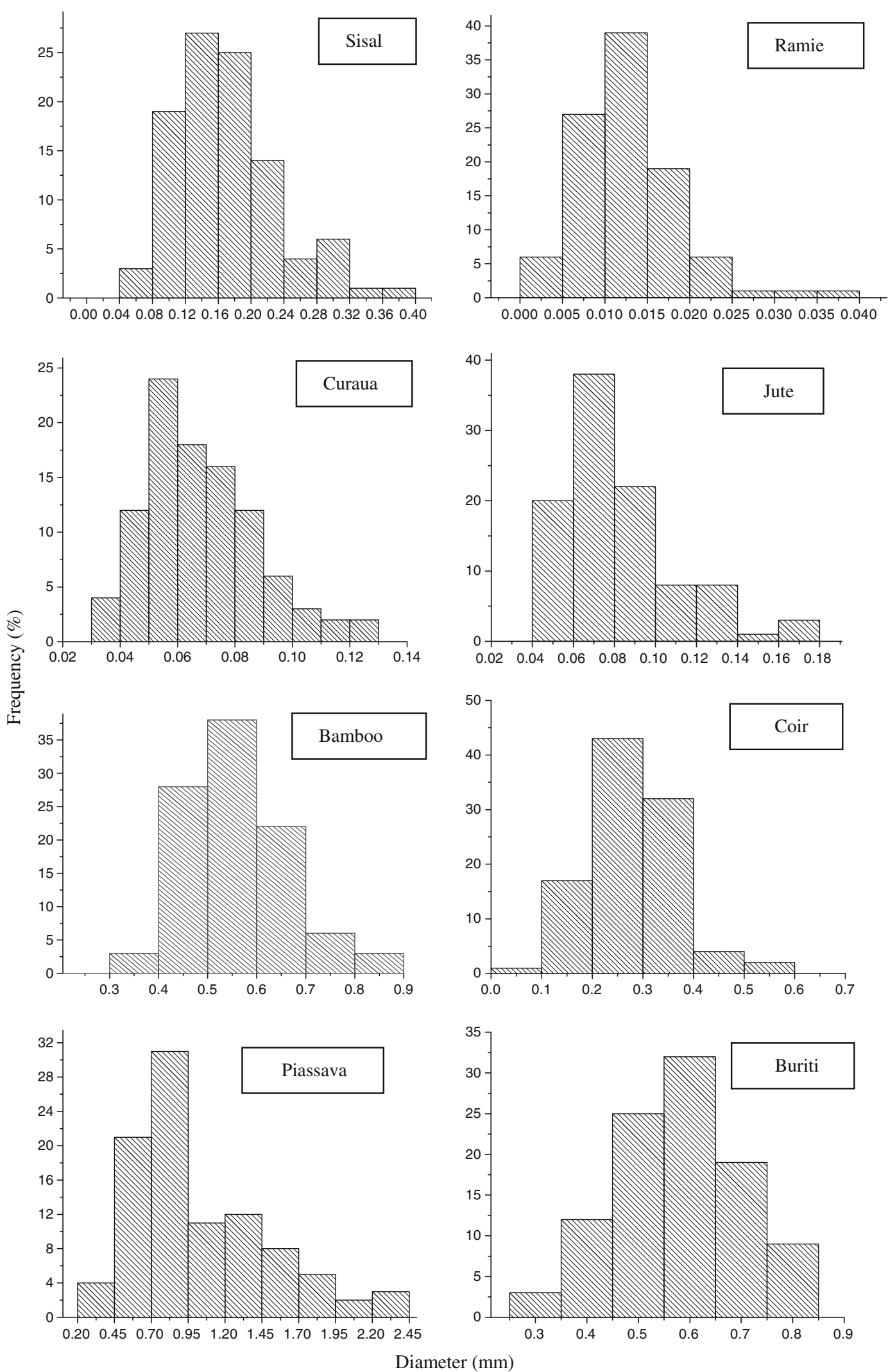

Fig. 3-Distribution frequency for the mean equivalent diameters of the eight investigated LCFs. 
(or fiber volume for the same test length) fit well a unimodal cumulative Weibull distribution function:

$$
F(x)=1-\exp \left[-(x / \alpha)^{\beta}\right]
$$

where $\alpha$ and $\beta$ are the shape and scale parameters, respectively.

As observed in Table I, a great dispersion of tensile strength values exists for every investigated LCF. In general, the minimum value is above $100 \mathrm{MPa}$, with the exception of coir with $95 \mathrm{MPa} .^{[23]}$ The maximum tensile strength values start at $143 \mathrm{MPa}$ for piassava ${ }^{[22]}$ and $175 \mathrm{MPa}$ for coir ${ }^{[4,20,23]}$ and extend up to $3000 \mathrm{MPa}$ for curaua. ${ }^{[23]}$ Considering the engineering common structural metallic materials such steels, copper, and titanium alloys, ${ }^{[32]}$ their tensile strength values are comparable to those (Table I) for LCFs. High-strength metallic alloys with ultimate tensile stress above $1000 \mathrm{MPa}$ could also be paired by LCFs. Indeed, earlier review articles ${ }^{[4,20-22]}$ reported on natural fibers reaching high tensile strengths. However, only a few fibers such as flax, ${ }^{[4,20]}$ pineapple, ${ }^{[20]}$ and curaua ${ }^{[23]}$ were found to attain tensile strength of the order of $1000 \mathrm{MPa}$.

\section{HIGH-STRENGTH LCFS}

The already mentioned recent works $^{[10-19]}$ on the tensile strength variation with the LCF equivalent diameter showed a consistent inverse correlation similar to what was earlier reported on pineapple. ${ }^{[4,8]}$ Consequently, very thin diameter LCFs could eventually be selected with relatively high strength. Figure 4 shows the Weibull average tensile strength from results presented elsewhere ${ }^{[10-18]}$ as a function of the equivalent diameter of corresponding statistical intervals.

For all curves in Figure 4, there is a clear tendency for an inverse relationship between the strength and the equivalent diameter. In other words, the thinner the diameter, the stronger the fiber will be. One point deserves attention in Figure 4. For the thinnest sisal $^{[11]}$ (Figure 4(a)), ramie ${ }^{[12]}$ (Figure 4(b)), curaua ${ }^{[13]}$ (Figure $4(\mathrm{c})$ ), and piassava ${ }^{[17]}$ (Figure $4(\mathrm{~g})$ ), values of tensile strength above $1000 \mathrm{MPa}$ were obtained.

These results corroborate the first previous work on the subject ${ }^{[10]}$ dealing with curaua, sisal, and ramie fibers. In particular, the inverse correlation between the strength and the equivalent diameter is an undoubted evidence for the stronger sisal, ramie, curaua, and piassava fibers. In Figure 4, no simple inverse straight lines are able to fit the points. It was commonly found ${ }^{[10-19]}$ that a simple hyperbolic inverse correlation could reasonably translate the variation of strength, $\bar{\sigma}$, with the fiber equivalent diameter, $d$ :

$$
\bar{\sigma}=A / d-B
$$

Table II shows the values of $A$ and $B$ in Eq. [2] associated with the hyperbolic equation for the nine lignocellulosic fibers considered. ${ }^{[10-19]}$ In this table, the correlation coefficients associated with the experimental fitting to the corresponding hyperbolic equation are also shown. These results revealed strong evidence that a nonlinear inverse correlation could rule the tensile strength $v s$ equivalent diameter relationship in lignocellulosic fibers. Although limited to only nine types of fibers, ${ }^{[10-19]}$ this behavior may also apply to other ones such as cotton, flax, hemp, kenaf, pineapple, and wood. The reason for a general relationship such as that associated with a hyperbolic Eq. [1] can be explained by the role played by defects and flaws in the fiber's structure. This will be discussed further in Section VI.

As a final comment regarding the results of Figure 4 and Table II, it is worth mentioning the consequence of a hyperbolic relationship. In principle, this relationship, generally expressed by Eq. [1], indicates that very high strengths could be attained by LCFs with very small cross-sectional dimensions, given by the equivalent diameter. Since any natural fiber has a limited range for its dimensional variation, one can only speculate about how much thinner in nature it can be. Consequently, to imagine the strongest value that can be reached by an LCF based on Eq. [1] is just a hypothesis. However, the experimental results so far obtained for some fibers such as sisal, ${ }^{[10,11]}$ ramie, ${ }^{[10,12]}$ curaua, ${ }^{[10,13]}$ and piassava $^{[17]}$ showed values above $1000 \mathrm{MPa}$. Even though $1000 \mathrm{MPa}$ may not be associated with any special threshold, it could represent a symbolic level of a high-strength material. In fact, most metallic alloys, ceramics, and polymeric materials possess tensile strengths below this level. ${ }^{[32]}$

\section{MICROSTRUCTURE AND FRACTURE ANALYSIS}

A possible explanation suggested, ${ }^{[10-19]}$ for the inverse tensile strength $v s$ diameter correlation, presented in Figure 4 and Eq. [2], was based defects and on the heterogeneous microstructure typical of any LCF. As shown in Figure 2 for the surface and in Figure 5 for the cross section, these fibers possess defects, flaws, and irregularities throughout their spatial three dimensions. In other words, lignocellulosic fibers are microstructurally nonuniform along any three-dimensional orientation. This is a marked difference to synthetic fibers (Figure 1), and certainly the major factor for the relatively lower strength performance of any natural fiber.

Experimentally, it was observed ${ }^{[10-19,25]}$ that the density of defects/flaws/irregularities in lignocellulosic fibers varies with equivalent diameter, i.e., the size of the cross section. Smaller cross sections present comparatively lower density of defects/flaws/irregularities, both in the surface and inside the volume of the fiber. As a consequence, thinner fibers tend to be more homogeneous than thicker ones of the same species. Examples of this behavior can be seen in the cross-sectional views in Figure 5. In this figure, one may notice that the smaller fibers have a tendency to be less eccentric, to be more circular, and to have less porosity. The aforementioned nonuniform distribution of defects/flaws/irregularities densities present by fibers with different cross-sectional sizes is apparently one of the main mechanisms responsible for the inverse strength $v s$ diameter correlation. 




(a)

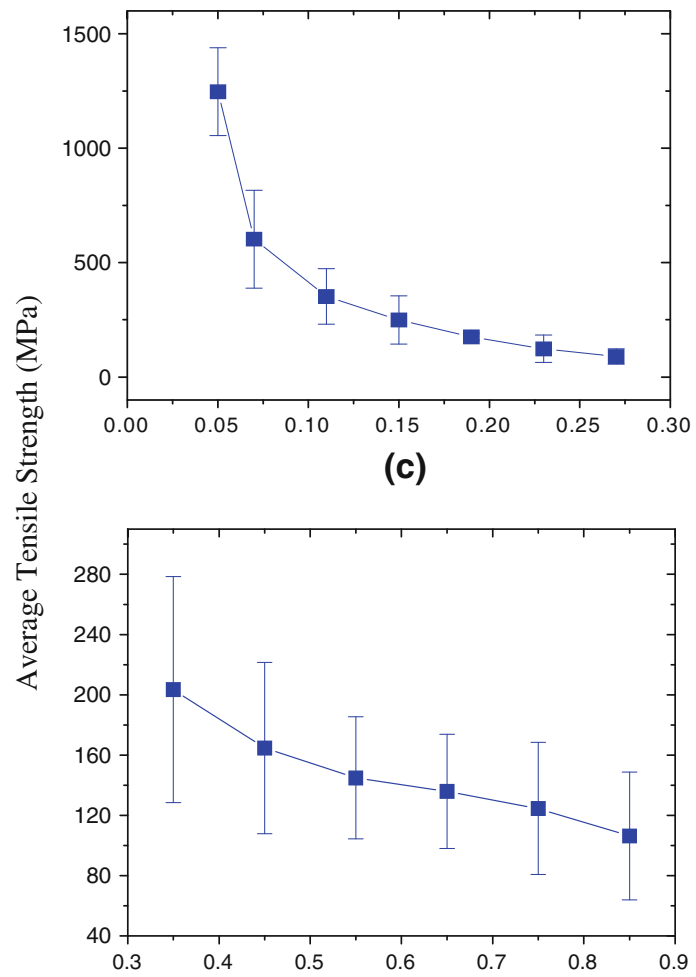

(e)

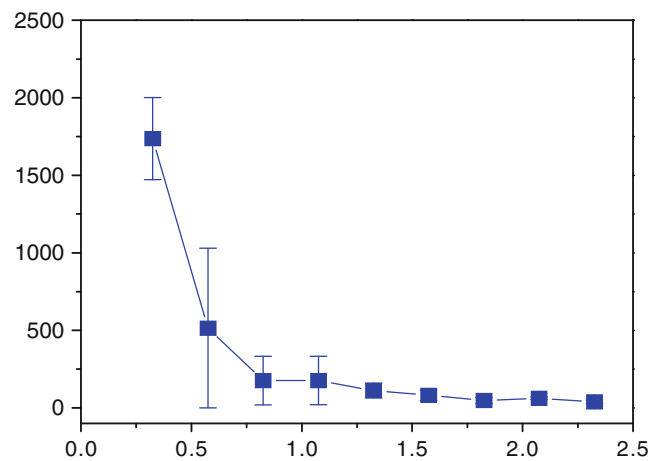

(g)

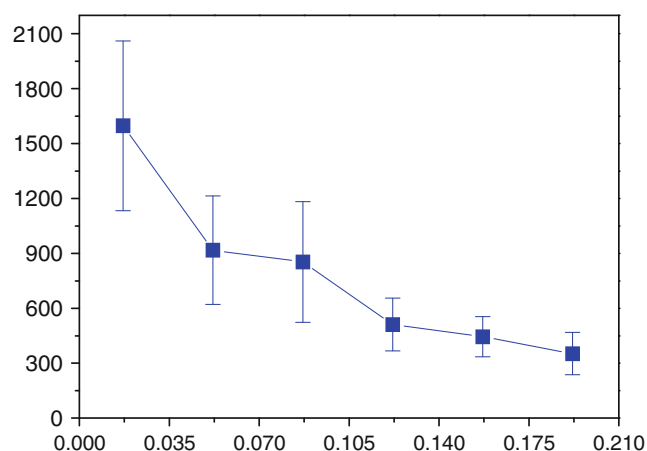

(b)



(d)

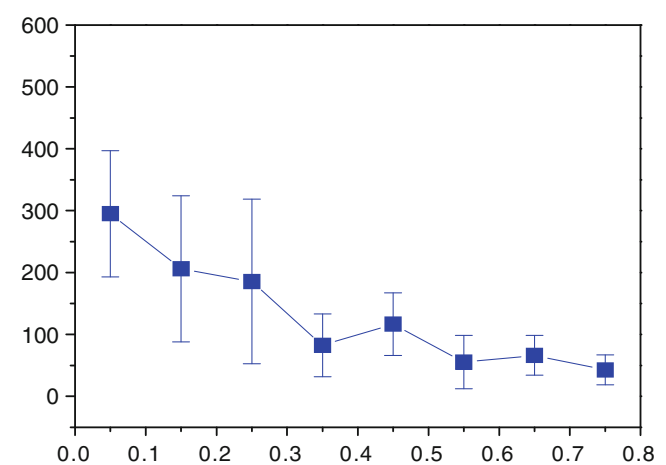

(f)

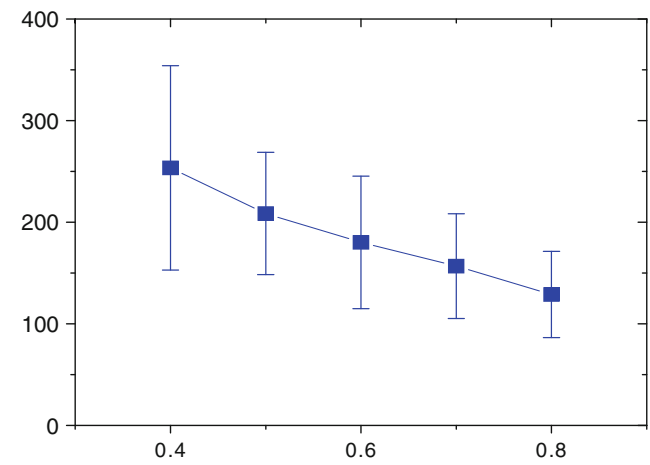

(h)

Fig. 4 -Weibull average strength as a function of the mean equivalent diameter for the LCFs: $(a)$ sisal,${ }^{[10,11]}(b)$ ramie, ${ }^{[10,12]}(c)$ curaua, ${ }^{[10,13]}(d)$ jute, ${ }^{[14]}(e)$ bamboo, ${ }^{[11]}(f)$ coir ${ }^{[16]}(g)$ piassava, ${ }^{[17]}$ and $(h)$ buriti. ${ }^{[18]}$

The most straightforward evidence of the mechanisms that causes the inverse correlation is provided by the SEM fractograph analysis of tensile-ruptured fibers in
Figure 6. In this figure, a comparison between the typical fracture of thinner and thicker fibers is presented. For all LCFs, it was observed that the thinner fibers 
Table II. Hyperbolic Coefficients for the Strength $(\bar{\sigma})$ vs Diameter (d) Relationship: $\bar{\sigma}=A / d-B$

\begin{tabular}{llllllllll}
\hline LCT & Sisal & Ramie & Curaua & Jute & Bamboo & Coir & Piassava & Buriti & Banana \\
\hline A (MPa·mm) & 39 & 21 & 67 & 19 & 54 & 13 & 620 & 96 \\
B (MPa) & 209 & 389 & -196 & -64 & 49 & 68 & -349 & 15 \\
Adjustment & 0.93 & 0.88 & 0.95 & 0.99 & 0.98 & 0.74 & 0.92 & 0.99 & 0.98 \\
$\quad$ coefficient $R^{2}$ & & & & & & & & & \\
\hline
\end{tabular}

display a rupture associated with more homogeneous microstructure and less participations of microfibrils. By contrast, the thicker fibers reveal a comparatively more heterogeneous rupture associated with relatively more microfibrils. It is worth emphasizing that microfibrils are common and apparently equal in all LCFs. They are based on cellulose chains and constitute the strongest part of the fiber. The difference in strength between fibers depends on the relative amount of microfibrils (cellulose composition) and lignin. It also depends on the spiral angle of microfibrils around the fiber axis. In fact, both this spiral angle and the content of cellulose/lignin determine the mechanical properties of a LCF. ${ }^{[4]}$

The fractograph results in Figure 6 indicate that, statistically, there is a higher probability that a thicker fiber would break at a stress lower than that required for a thinner fiber. First, as observed, ${ }^{[1-19]}$ the thicker fibers with larger cross section apparently have a higher density of defects/flaws/irregularities. These correspond to weaker points and stress raisers that cause premature failure in comparison to thinner fibers. Second, owing to the greater dispersion in properties of lignocellulosic fibers, ${ }^{[4,20-23]}$ a thicker fiber with more microfibrils has statistically a comparative larger distribution of both weaker and stronger microfibrils. Consequently, during the tensile test, there is a higher probability that a weaker microfibril in the thicker fiber breaks at a lower stress than the weaker microfibril in the thinner fiber. Once the first microfibril (weakest of the thicker fiber) is broken, it causes a flaw in the fiber structure. The flaw may act as a microcrack, which swiftly propagates in a brittle mode until total rupture. In other words, statistically, the group of many microfibrils composing a thicker fiber tends to have one of them breaking shortly during the tensile load as compared to any of the fewer microfibrils of a thinner fiber. These two proposed mechanisms support the inverse tensile strength correlation with the equivalent diameter. Furthermore, the observed unimodal Weibull distribution, Eq. [1], for the investigated LCFs clearly indicates that fibers with smaller diameters should be stronger than the ones of the same species with greater diameter.

\section{LCFS IN A STRENGTH-DENSITY CHART}

The increasing technical use of LCFs, particularly as reinforcement of polymer composites for automobile components, ${ }^{[27-30]}$ now requires the recognition that they represent a relevant class of engineering material. In addition to important practical advantages such as lower density and cost, it was shown in the PW that tensile strength comparable to the stronger metallic alloys can be selected in thinner fibers. In fibers such as flax, pineapple, sisal curaua, ramie, and piassava, tensile strengths above $1000 \mathrm{MPa}$ actually have been observed. In other LCFs, this may be attained if sufficiently thin fibers could be selected. Therefore, one may begin to consider LCFs as possible high-strength materials with a specific field in Ashby's Material Property Charts. It is not the aim of the PW to discuss details of the insertion of all known LCFs in charts as was done for BMGs. ${ }^{[3]}$ Nevertheless, it was considered relevant to provide a preliminary insight on the proper location of LCFs in a chart comprising important structural properties, namely, tensile strength vs density. Thus, Figure 7 displays in this chart a probable ellipse-shaped field for LCFs. Enclosed fields for some species are also shown. The limits of this field are based on the results presented in Table I, i.e., strengths from 95 to $3000 \mathrm{MPa}$ and densities from 0.45 to $1.60 \mathrm{~g} / \mathrm{cm}^{3}$.

In Figure 7, two points are worth noticing. First, the LCFs stand out at the upper left side of the chart with their highest strength values at a similar level of the engineering composites and engineering alloys. Second, considering the chart's guidelines, LCFs would be the best choice for selection based on minimum weight design with $\sigma^{2 / 3} / \rho$ and $\sigma^{1 / 2} / \rho$ modes of loading. In fact, by translating the corresponding guidelines sideways, the limiting point where a material still exists is the tangent at the upper-left point of the LCF field. For this selection, not even in the "engineering ceramics" field, a material would be found with higher $\sigma^{2 / 3} / \rho$ and $\sigma^{1 / 2} / \rho$ values.

It could be argued that LCFs are not bulk materials and, therefore, have inherent limited application as structural components. As fiber materials, however, today they compete with glass, carbon, aramid, and other synthetics traditionally used as composite reinforcement. ${ }^{[26,29]}$ Despite the already discussed restrictions, LCFs need to gain priority as natural alternatives to pollution, energy saving, and environmental problems that are of serious concern regarding the future of mankind on planet earth. The recognition of LCFs as a new class in a privileged position (Figure 7) among the engineering materials will contribute to promoting applications, especially those associated with highstrength selected thinner fibers. Preliminary works ${ }^{[10,33,34]}$ on the reinforcement of polymeric matrices with these thinner LCFs indicated a consistent increase in the mechanical strength of the composites. Moreover, future technological development may facilitate processing techniques to separate thinner fibers from a general lot. Actually, a promising technique is currently being primarily applied by the authors of this 

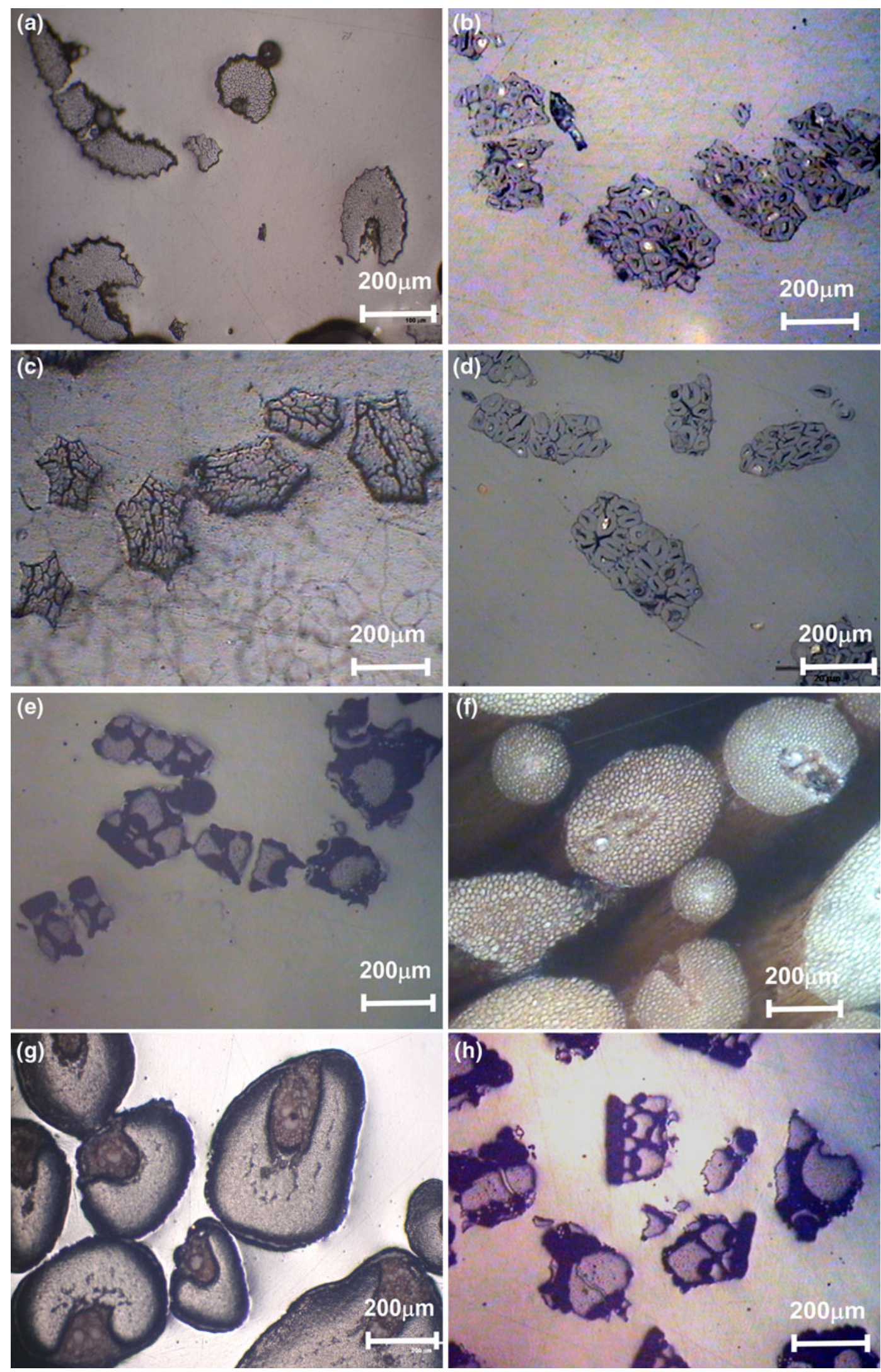

Fig. 5-Typical cross section of LCFs: $(a)$ sisal, $(b)$ ramie, $(c)$ curaua, $(d)$ jute, $(e)$ bamboo, $(f)$ coir, $(g)$ piassava, and $(h)$ buriti. 


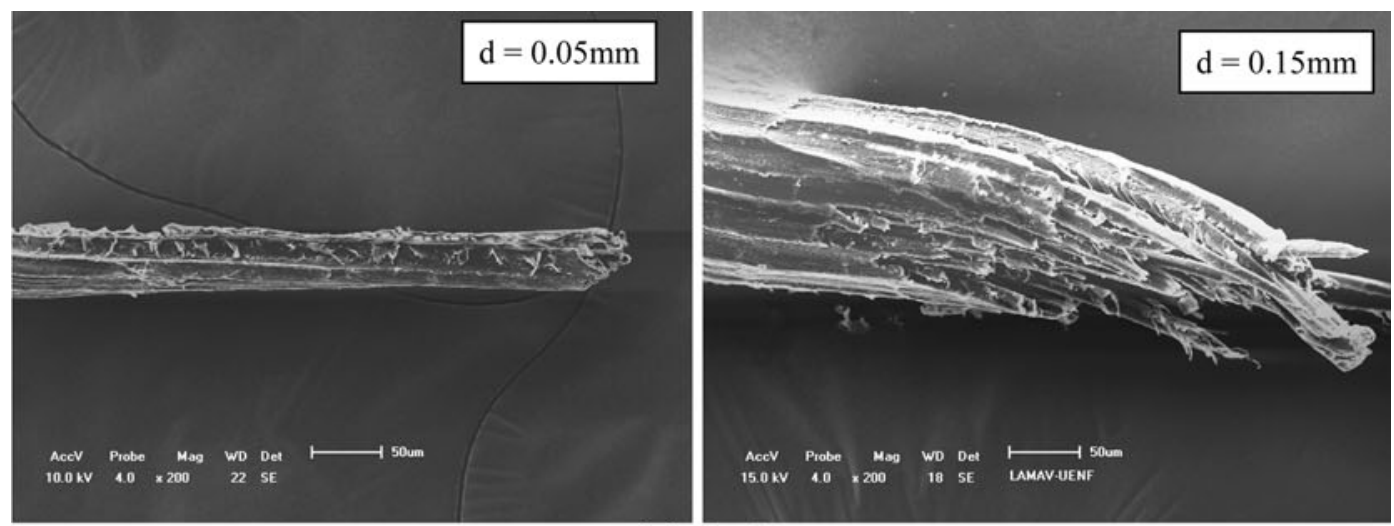

(a) Sisal

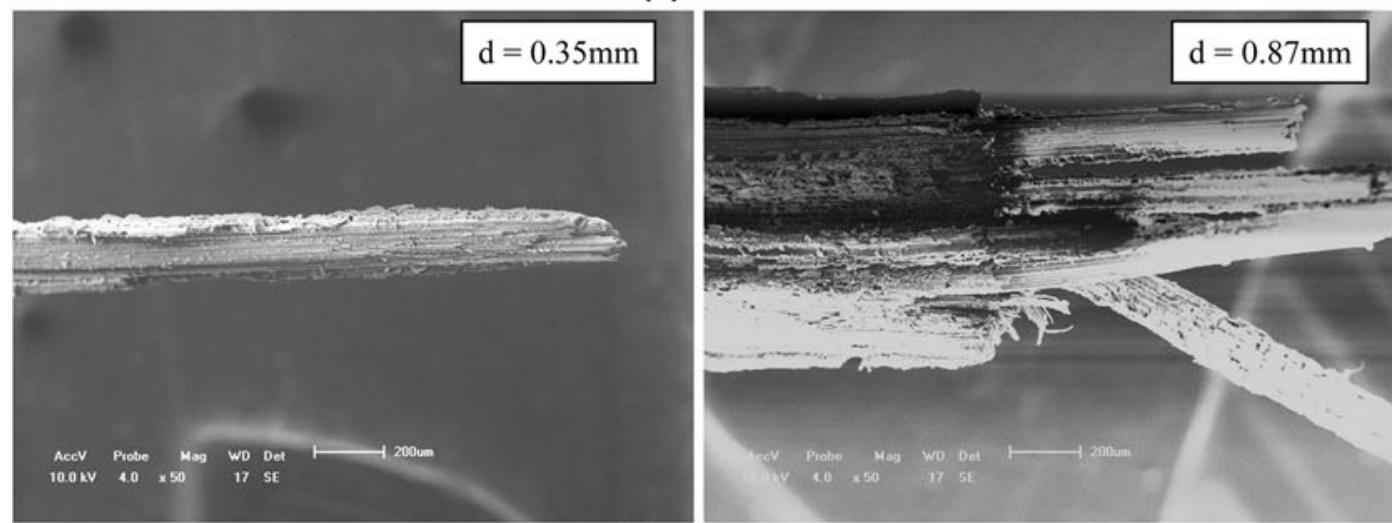

(b) Bamboo



(c) Coir

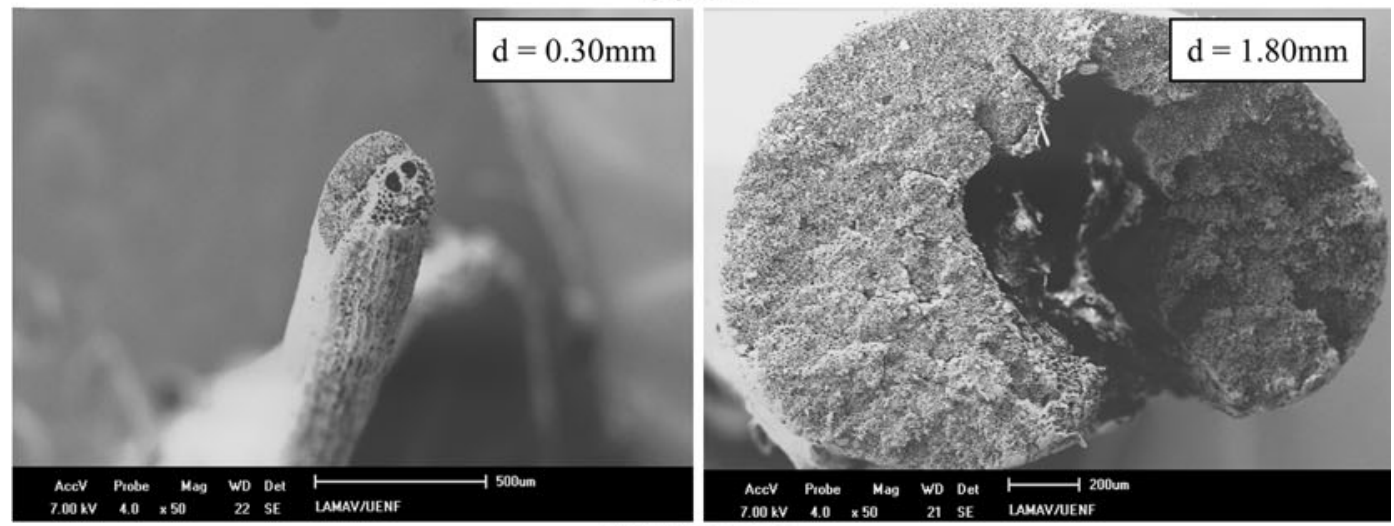

(d) Piassava

Fig. 6 - SEM fractographs of tensile-ruptured tips of thin and thicker fibers for LCFs: $(a)$ sisal, ${ }^{[1]}(b)$ bamboo, ${ }^{[15]}(c)$ coir, ${ }^{[16]}$ and $(d)$ piassava. ${ }^{[17]}$ 


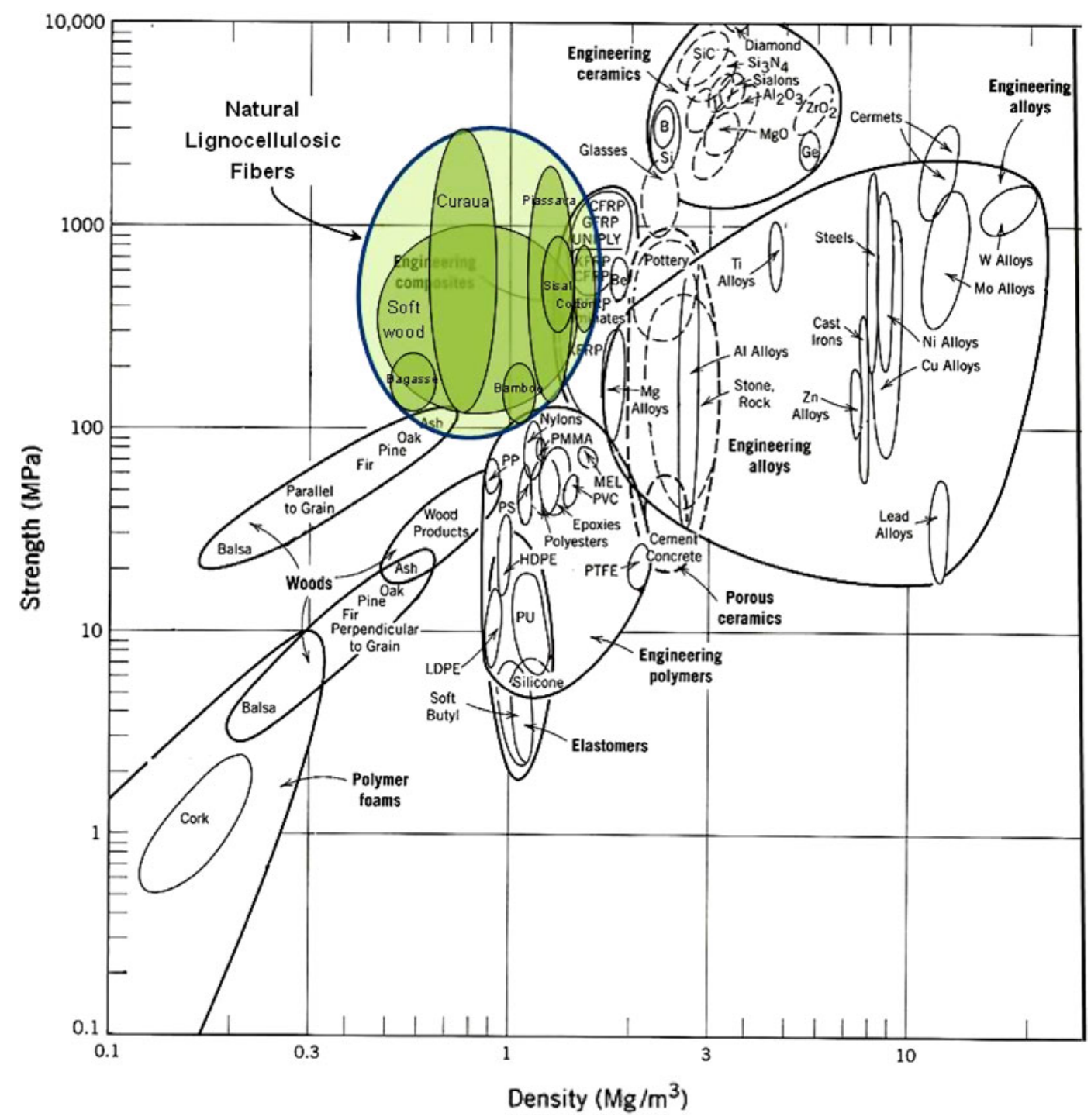

Fig. 7-The LCF field in an Ashby's $\sigma v s \rho$ chart.

overview to select fibers of certain diameters within a lot of the same species. This method is based on the sensible difference in densities, which exists for distinct diameters. Using a fluid with intermediate density (for instance, water with convenient salt concentration), it is possible to separate the same species of LCF by their diameters. Eventually, LCFs drawbacks such as structural defects and dimension heterogeneities will be attenuated by genetic selection allowing a further improvement in properties.

\section{CONCLUDING REMARKS}

While the use of natural LCFs in simple items has been exploited since the beginning of our civilization, their applications as engineering materials have only received attention in the past decades. Environmental as well economical and social benefits motivated these applications. In particular, technical advantages such as lower density, less wear of processing equipment, and higher flexibility justified the increasing use in composites for automobile components. The PW overviews experimental results, indicating that high-strength LCFs can be selected from those with thinner diameter. Relatively fewer amounts of defects are one of the reasons for the inverse correlation between tensile strength and LCF diameter. It is then proposed that a proper field for the LCFs be introduced in the Ashby's Material Property Charts as a new class of engineering materials. This LCF field stands out, in a strength $v s$ density chart, among other engineering fields encompassing the highest strength materials corresponding to composites, metallic alloys, and ceramics. According to the structural conditions for minimum weight design with $\sigma^{2 / 3} / \rho$ and $\sigma^{1 / 2} / \rho$ modes of loading, LCFs might be the engineering selection over any other existing material. 


\section{ACKNOWLEDGMENTS}

The authors thank the support of this investigation by the Brazilian agencies CNPq, CAPES, FAPERJ, FINEP, and TECNORTE/FENORTE. We also acknowledge the permission by the PEMM from COPPE/UFRJ to use the SEM microscope.

\section{REFERENCES}

1. M.F. Ashby: Acta Metall., 1989, vol. 37 (5), pp. 1273-93.

2. M.F. Ashby: Materials Selection in Mechanical Design, 2nd ed., Butterworth-Heinemann, Woburn, United Kingdom, 2002.

3. M.F. Ashby and A.L. Greer: Scripta Mater., 2006, vol. 54, pp. 321-26.

4. A.K. Bledzki and J. Gassan: Prog. Polym. Sci., 1999, vol. 4, pp. 221-74.

5. A.G. Kulkarni, K.G. Satyanarayana, K. Sukumaran, and P.K. Rohatgi: J. Mater. Sci., 1981, vol. 16, pp. 905-14.

6. A.G. Kulkarni, K.G. Satyanarayana, P.K. Rohatgi, and K. Vijayan: J. Mater. Sci., 1983, vol. 18, pp. 2290-96.

7. P.S. Murherjee and K.G. Satyanarayana: J. Mater. Sci., 1984, vol. 19, pp. 3925-34.

8. P.S. Mukherjee and K.G. Satyanarayana: J. Mater. Sci., 1986, vol. 21, pp. 51-56.

9. P.S. Murherjee and K.G. Satyanarayana: J. Mater. Sci., 1986, vol. 21, pp. 57-63.

10. S.N. Monteiro, K.G. Satyanarayana, and F.P.D. Lopes: Mater Sci. Forum, 2010, vols. 638-642, pp. 961-66.

11. W.P. Inacio, F.P.D. Lopes, and S.N. Monteiro: Proc. Biomaterials Symp., 1st TMS-ABM Int. Mater. Congr, Rio de Janeiro, Brazil, 2010, pp. 1-10.

12. F.M. Margem, J. Bravo Neto, and S.N. Monteiro: Proc. 19th Brazilian Congr. on Materials Science and Engineering, Campos do Jordão, Brazil, 2010, pp. 1-10 (in Portuguese).

13. A.S. Ferreira, S.N. Monteiro, and F.P.D. Lopes: Proc. 64th Int Congr. of the Brazilian Association for Metallurgy and Materials, Belo Horizonte, Brazil, 2009, pp. 1-12 (in Portuguese).

14. A.B. Bevitori, I.L.A. Silva, and S.N. Monteiro: Proc. Biomaterials Symp., 1st TMS-ABM Int. Materials Congr, Rio de Janeiro, Brazil, 2010, pp. 1-10.
15. L.L. Costa, R.L. Loiola, and S.N. Monteiro: Proc. Biomaterials Symp., 1st TMS-ABM Int. Materials Congr, Rio de Janeiro, Brazil, 2010, pp. 1-10.

16. H.P.G. Santafe, Jr., S.N. Monteiro, and L.L. Costa: Proc. 64th Int. Congr. of the Brazilian Association for Metallurgy and Materials, Belo Horizonte, Brazil, 2009, pp. 1-12 (in Portuguese).

17. D.C.O. Nascimento, L.C. Motta, and S.N. Monteiro: Proc. Characterization of Minerals, Metals and Materials SymposiumTMS Conf, Seattle, WA, 2010, pp. 1-8.

18. T.G.R. Portela, L.L. Costa, F.P.D. Lopes, and S.N. Monteiro: Proc. Characterization of Minerals, Metals and Materials Symp.TMS Conf, Seattle, WA, 2010, pp. 1-7.

19. F.P.D. Lopes, N.C.G. Rosa, L.B.S. Martins, and S.N. Monteiro: Proc. 19th Brazilian Congress on Materials Science and Engineering, Campos do Jordão, Brazil, 2010, pp. 1-8 (in Portuguese).

20. A.K. Mohanty, M. Misra, and G. Hinrichsen: Macromol. Mater. Eng, 2000, vols. 276-277, pp. 1-24.

21. S.J. Eichhorn, C.A Baillie, and N. Zafeiropoulos: J. Mater. Sci., 2001, vol. 36, pp. 2107-13.

22. D. Nabi-Sahed and J.P. Jog: Adv. Polym. Technol., 1999, vol. 18, pp. 221-74.

23. K.G. Satyanarayana, J.L. Guimarães, and F. Wypych: Compos. Part A, 2007, vol. 38, pp. 1694-1709.

24. S. Kalia, B.S. Kaith, and I. Kaur: Polym. Eng. Sci., 2009, vol. 49, pp. $1253-72$

25. S.N. Monteiro, F.P.D. Lopes, A.S. Ferreira, and D.C.O. Nascimento: JOM, 2009, vol. 61, pp. 17-22.

26. P. Wambua, I. Ivens, and I. Verpoest: Comp. Sci. Technol., 2003, vol. 63, pp. 1259-64.

27. S. Hill: New Scientists, 1997, vol. 153, pp. 36-39.

28. G. Marsh: Mater. Today, 2003, vol. 6, pp. 36-43.

29. J. Holbery and D. Houston: JOM, 2006, vol. 61, pp. 80-86.

30. R. Zah, R. Hischier, and A.L. Leão: J. Clean Prod., 2007, vol. 15, pp. $1032-40$.

31. C. Klason, J. Kubat, and H.-E. Strömvall: Int. J. Polym. Mater., 1984, vol. 10, pp. 159-87.

32. W.D. Callister, Jr.: Materials Science and Engineering-An Introduction, 7th ed., John Wiley \& Sons, New York, NY, 2007.

33. D.C.O. Nascimento, I.L.A. Silva, A.B. Bevitori, F.P.D. Lopes, and S.N. Monteiro: Proc. Characterization of Minerals, Metals and Materials Symp.-TMS Conf, San Diego, CA, 2011, pp. 1-8.

34. L.L. Costa, S.N. Monteiro, and R.L. Loiola: Proc. Characterization of Minerals, Metals and Materials Symp.-TMS Conf., San Diego, CA, 2011, pp. 1-8. 